\title{
Assessment of drug utilization pattern and rationality of drug use in treatment of dilated cardiomyopathy in a tertiary care teaching hospital of rural Bengal
}

\author{
Prasun Banerjee, Ananya Mandal*, Dipankar Mukhopadhyay, Tanmoy Gangopadhyay, \\ Sonai Mandal, Abhijit Das
}

\begin{abstract}
Department of Pharmacology, Bankura Sammilani Medical College, Bankura, West Bengal, India
\end{abstract}

Received: 22 October 2016 Accepted: 17 November 2016

*Correspondence to:

Dr. Ananya Mandal,

Email:

drananyamandal@gmail.com

Copyright: (c) the author(s), publisher and licensee Medip Academy. This is an openaccess article distributed under the terms of the Creative Commons Attribution NonCommercial License, which permits unrestricted noncommercial use, distribution, and reproduction in any medium, provided the original work is properly cited.

\begin{abstract}
Background: Dilated cardiomyopathy (DCM) is an important underlying cause of congestive heart failure and/or arrhythmias. The introduction of therapy combining diuretics, digoxin and angiotensin converting enzyme inhibitors (ACEI) has significantly decreased mortality and morbidity. The aim of the study was undertaken to identify the pattern of drugs most commonly prescribed for DCM and to assess the rationality behind such use.

Methods: This was a prospective study undertaken between 1st July and 31st August 2015. Prescriptions were reviewed and analyzed using the World Health Organization (WHO) indicators for drug utilization studies. Rationality and cost of therapy per prescription was also evaluated.

Results: We encountered 78 patients of DCM in the OPD of Cardiology (prevalence of $4.94 \%$ ). The average number of drugs per prescription was 6.64. Generic prescriptions were made in $90 \%$ encounters. As part of therapy, diuretics and ACE inhibitors or angiotensin receptor blockers, were prescribed in all cases. Our results show a distinctive drug use pattern where beta blockers were used more commonly than digoxin. Other commonly prescribed agents were antiplatelet drugs and statins. Antibiotics were prescribed in $8.7 \%$ cases and no injectable drug was prescribed. Average drug cost per encounter was 10.63 INR.

Conclusions: To conclude, we found a typical and rational pattern of drug use. Diuretics, ACEI and beta blockers were found to be most commonly used agents. This study provides a clear picture of drug use in this special clinical condition in rural Bengal and paves the way for larger and long term studies.
\end{abstract}

Keywords: ACE inhibitors, Beta blockers, Dilated cardiomyopathy, Diuretics, Digoxin, Heart failure

\section{INTRODUCTION}

Dilated cardiomyopathy (DCM) persists to be a poorly understood and less analyzed group of cardiac-muscle disorder. It is characterized by thinning and weakness of the heart muscle. The combination of dilatation and systolic dysfunction of the left or both ventricles from idiopathic or specific origin define DCM. It can affect 5-8 per 100,000 people, per year with a prevalence of $0.04 \% .^{1}$ DCM is an important underlying cause of congestive heart failure and/or arrhythmias. Among the various causes of DCM, ischemic heart disease, valvular cardiomyopathy (AS), alcohol or virus induced DCM are predominant. The introduction of therapy combining diuretics, digoxin and angiotensin converting enzyme inhibitors (ACEI) along with beta blockers, spironolactone and vasodilators like nitrates has significantly decreased mortality and morbidity. ${ }^{2,3}$

In recent past the Drug Utilizing Studies (DUS) are undertaken quite frequently implying that inappropriate drug use is a universal phenomenon the search for rational therapy is an earnest one. The impact of these studies is great in medical, economical and also in social fields in order to determine the prescribing patterns and to set priorities to avoid the irrational drug use.

It has been reported that drug treatment is more effective only when patients know about the therapy. Prescription auditing and drug utilization studies are some of the 
fundamental steps towards improving habit of prescription and its quality and rationality of medication. Rational use of drugs represents that patients receive drugs according to the clinical needs for an optimum period and at a minimum price. Misunderstanding over brand names, price, irregular drug supply, non-existence of drug formularies in the hospital and lack of knowledge and awareness among patients regarding proper dosing schedule are some of the major causes of irrational drug use that may lead to inadequate therapeutic effects, undesirable drug events, drug interactions and long term damage to the patient-physician relationship. ${ }^{4-7}$

Previously, the risk of cardio vascular disease and drug utilization patterns were done in various settings but there is lack of similar studies among patients with dilated Cardiomyopathy, its incidence and monitoring or use of drugs in this setting. From our experience in the Cardiology department, we noted that there is a high incidence of dilated cardiomyopathy among patients visiting the OPD compared to cite figures. This intrigued us and we sought to find the management patterns as well as the epidemiological details of these patients in a pilot study. In the present study we examined the prescription in the OPD and also interviewed the patient about the use of drug and his satisfaction and compliance about the treatment received.

\section{METHODS}

This was a prospective, observational study performed at the Cardiology Clinic at the Department of Cardiology, at a tertiary care Medical College in rural West Bengal, for the duration of 2 months starting from 1st July to 31st August 2015. As per inclusion criteria, we enrolled all the patients diagnosed by a consultant cardiologist to have as having dilated Cardiomyopathy with heart failure levels at New York Heart Association (NYHA) class II or III. As per exclusion criteria, patients with chronic pulmonary obstructive disease (COPD), post radiotherapy patients and those with NYHA-IV heart failure were not included in the study. Data were collected by analyzing the prescriptions and the patients were also interviewed about treatment. The consultation time for each patient was also recorded as one of our investigators was present during the doctor-patient interview. Only one encounter prescriptions were selected from the prescriptions collected. Detailed clinical and drug history, past history, co-morbidities, concomitant medications taken, relevant laboratory investigations were collected and thoroughly analyzed to reach at a clinical diagnosis.

The following drug utilization study indicators were evaluated: ${ }^{4}$ (1) Core drug prescribing indicators: (a) average number of drugs per encounter (b) percentage of drugs prescribed by generic names (c) percentage of encounters with an antibiotic (d) percentage of encounters with an injection (e) percentage of drugs prescribed from the essential drugs list or formulary. The other indicators include "Core health facility indicators" viz (a) availability of key drugs (b) availability of a copy of essential drug list or formulary. The Complementary indicators that were evaluated were:

- Whether prescriptions were in accordance with standard treatment guidelines

- Average dispensing time

- Percentage of drugs actually dispensed

- Percentage of drugs adequately labeled

- Patient's knowledge of correct dosage.

Some of the other complementary indicators like average consultation time, were not assessed as they could not be determined accurately at the pharmacy. Moreover, drug data, including name of the drug, dosage schedule (form, route, frequency and duration) and duration of pharmacotherapy were recorded. All drugs were coded as per the WHO Anatomical Therapeutic and Chemical Classification coding system (ATC). ${ }^{4,5}$ Adherence to the WHO Daily Defined Dose (DDD) for each drug used could not be evaluated.

All information were collected and recorded in a Microsoft Excel datasheet maintained at the Department of Pharmacology. The statistical analysis was done using tools of descriptive statistics with the help of SPSS version 22. Prior approval of Institutional Ethics Committee was taken and informed consent was taken from the patients or their legal representatives.

\section{RESULTS}

In our study we encountered a total of 78 subjects over a period of two months. A total of 1576 patients were enrolled in the Cardiology OPD during this period with various indications. Thus, we noted the prevalence of DCM was $4.94 \%$. This is higher than the known incidence and prevalence of this condition. ${ }^{1} \mathrm{We}$ noted most of the patients were male $(71.79 \%$ or 56$)$ and most of them belonged to New York Heart Association (NYHA) classification of heart failure class II $(75.64 \%$ or 59 patients). As expected, most of the population encountered in our study, were aged between 50 to 60 years $(48.71 \%)$ followed by one third of the study population between ages 40 and 50 years and $17.94 \%$ patients being over 60 years of age. We analyzed the etiological distribution among patients with DCM and noted ischemic heart disease to be the most common cause leading to DCM (36\%) followed by valvular Cardiomyopathy (32\%), viral etiology (17\%) and alcoholic Cardiomyopathy (15\%) cases.

We analyzed a total of 78 prescriptions in which 518 drugs were prescribed. Analysis of the WHO Core and Complementary drug-prescribing indicators is summarized in Table 1 and 2. The Core Health facility indicators were evaluated and it was found that a copy of essential drug list or formulary was present in the outdoor and $85 \%$ of the key drugs were available to the patient from the pharmacy. In addition other findings were that 
average consultation time was 6.48 minutes per patient and average cost per encounter was around 10.63 INR.

\section{Table 1: Assessment of WHO core prescribing indicators.}

\begin{tabular}{|ll|}
\hline Parameters assessed & \\
\hline Average number of drugs per prescription & 6.64 \\
\hline $\begin{array}{l}\text { Percentage of drugs prescribed by generic } \\
\text { name }\end{array}$ & $90 \%$ \\
\hline $\begin{array}{l}\text { Percentage of encounters with an } \\
\text { antibiotic prescribed }\end{array}$ & $8.7 \%$ \\
\hline $\begin{array}{l}\text { Percentage of encounters with an injection } \\
\text { prescribed }\end{array}$ & $0 \%$ \\
\hline $\begin{array}{l}\text { Percentage of drugs prescribed from } \\
\text { essential drug list (National list of essential } \\
\text { medicine 2011) }\end{array}$ & $66.66 \%$ \\
\hline
\end{tabular}

Table 2: Assessment of WHO complementary prescribing indicators.

\begin{tabular}{|ll|}
\hline Parameters assessed & \\
\hline $\begin{array}{l}\text { Whether prescriptions were in } \\
\text { accordance with standard treatment } \\
\text { guidelines }\end{array}$ & $100 \%$ \\
\hline Average dispensing time & $\begin{array}{l}1.26 \\
\text { minutes }\end{array}$ \\
\hline Percentage of drugs actually dispensed & $85 \%$ \\
\hline Percentage of drugs adequately labeled & $100 \%$ \\
\hline Patient's knowledge of correct dosage & $49.06 \%$ \\
\hline
\end{tabular}
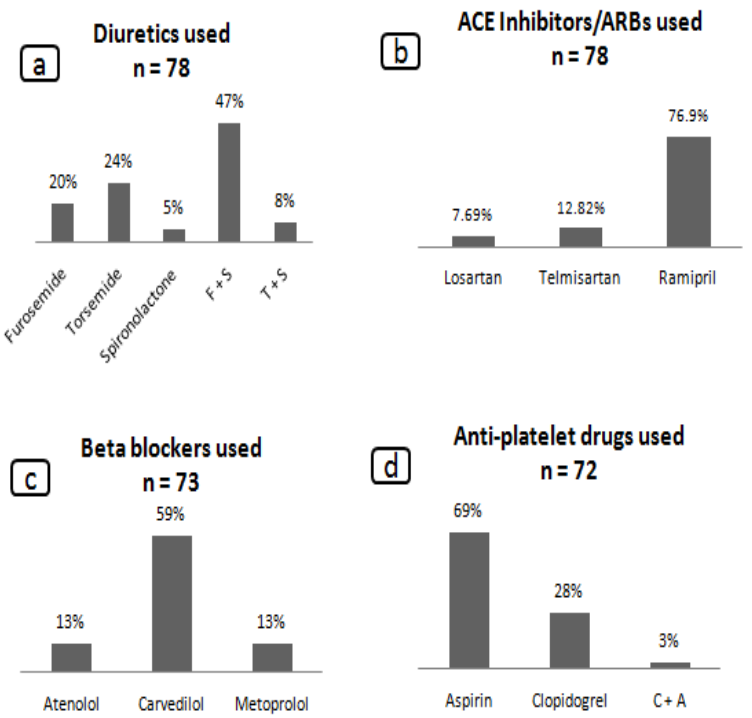

$* \mathrm{~F}+\mathrm{S}$ - Furosemide and Spironolactone; $\mathrm{T}+\mathrm{S}$ - Torsemide and Spironolactone; ACEI - Angiotensin converting enzyme inhibitors; ARBs - Angiotension receptor blockers; C + A Clopidogrel and Aspirin

Figure 1: Distribution of use of major cardiovascular drugs. a) Use of diuretics. b) Use of ACE inhibitors or ARBs c) Use of beta blockers d) Use of antiplatelet agents.
We went on to analyze the individual drugs prescribed in our set up. We found that diuretics were prescribed widely to all the patients. In addition all patients were also prescribed ACE inhibitors or Angiotensin receptor blockers with Ramipril being the most commonly prescribed agent. Similarly beta blockers were widely used in $93.58 \%$ cases with Carvedilol being the most commonly prescribed agent. Most of the patients were prescribed an antiplatelet drug $(92.3 \%)$ of which low dose Aspirin was most commonly prescribed (69\%). These four groups of agents prescribed commonly to most patients indicate a rational therapy as laid down by most standard treatment guidelines. Figure 1 shows the distribution of various cardiovascular drugs used among our study subjects.

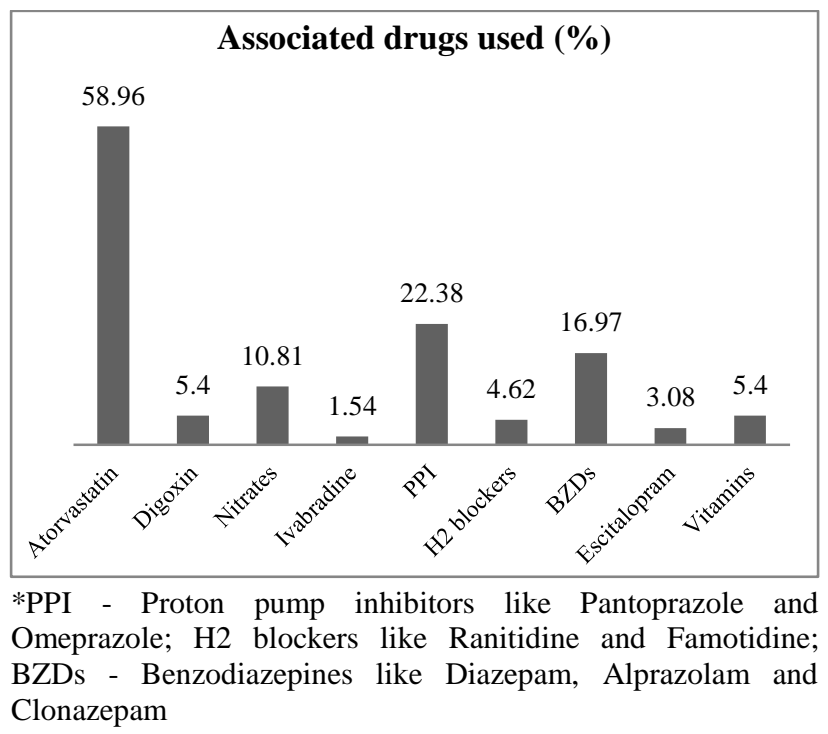

Figure 2: Other cardiovascular and noncardiovascular drugs that were prescribed in the study.

Table 3: Common regimen of drugs prescribed in Dilated Cardiomyopathy in our study.

\begin{tabular}{|lc|}
\hline Drugs prescribed & Percentage \\
\hline $\begin{array}{l}\text { ACEI/ARB* + Beta blocker + Diuretic } \\
+ \text { Antiplatelet + Statin }\end{array}$ & $48.71 \%$ \\
\hline $\begin{array}{l}\text { ACEI/ARB* + Diuretic + Beta blocker } \\
\text { + Digoxin }\end{array}$ & $12.82 \%$ \\
\hline $\begin{array}{l}\text { ACEI/ARB* + Beta blocker + Diuretic } \\
+ \text { Statin }\end{array}$ & $10.25 \%$ \\
\hline $\begin{array}{l}\text { ACEI/ARB* + Diuretics + Digoxin + } \\
\text { Antiplatelet }\end{array}$ & $7.69 \%$ \\
\hline & ACEI - Angiotensin Converting Enzyme Inhibitor; ARB - \\
\hline
\end{tabular}

Angiotensin receptor blocker

Among non-cardiovascular agents we noted a good number of prescriptions including proton pump inhibitors and statins. Anxiolytics were used in quite a few prescriptions due to the high prevalnece of anxiety and insomnia associated with chronic heart disease. The 
distribution of use of other cardiovascular and non cardiovascular drugs is shown in Figure 2.

Most of the drugs were prescribed according to guidelines and the regimens were found to be rational. However associated or underlying diseases and other conditions led to increase in the number of prescribed drugs per prescription. Table 3 shows the most common combination or regimen of drugs that were prescribed.

\section{DISCUSSION}

To our knowledge, this was the first study to look at drug usage among patients with Dilated Cardiomyopathy. We noted a male preponderance with most patients aged over 40 years. Similar demographic profile and findings has been reported from studies from India and from a European study among heart failure patients. ${ }^{1-3,6-8}$

The exact cause of DCM is still not clear but a number of diseases have been noted to increase the predisposition to develop DCM. ${ }^{1}$ Most of the patients have an ischemic, alcohol, viral infection pathology and use of nitrates along with other medications is widely prevalent in this group of patients. One of the reasons for this high prevalence in our setup may be due to improper management of the etiological diseases or patients' poor knowledge about the symptoms, lack of appropriate medical care and follow up and in general a gross neglect to health. While cited prevalence of this condition is $0.04 \%$ we, in our pilot project noted a prevalence of $4.94 \%$ of this condition.

Despite extensive search we did not find any studies pertaining to this condition from India or abroad. DCM is rising in its prevalence and clinical importance especially due to lack of awareness and patient adherence to management of other long term cardiovascular ailments. There is a drug utilization study among patients with heart failure in a South Indian tertiary care hospital reported by Bharath et al $2015 .^{9}$ DCM was found to be $4.67 \%$ of the study population with heart failure. In our study we found around 5\% of the total patients attending the cardiology OPD to be diagnosed with DCM. Drug use pattern in the study was similar to ours. Similarly Baskota et al, also reported a drug utilization study among patients with heart failure in Nepal. ${ }^{10}$ In their study nearly $25 \%$ of the patients of heart failure were diagnosed to be suffering from DCM. This is considerably higher than that reported by Bharath et al. ${ }^{9}$ They noted a high use of diuretics, ACE inhibitors and digoxin. Their drug use pattern is similar to our findings.

Despite noting a rational trend in prescribing, for obvious reasons the average number of drugs per prescription was 6.64 which is quite high. A heartening trend was $90 \%$ prescriptions being in generics and $85 \%$ of the drugs being actually dispensed. In addition the average cost per encounter was around 10.63 INR. This study being conducted in a tertiary care hospital in a rural area, this low cost of therapy points towards a rational choice of agents that is affordable to the patients. Drug compliance is one of the first areas that is affected if the cost of therapy is high especially for patients who are on long term pharmacotherapy. We however found that patient knowledge regarding correct dosage and administration to be lacking and an area that needs to be improved upon.

On analysis of the prescriptions we noted that diuretics formed part of all prescriptions with Spironolactone being a significantly prescribed agent. Due to the long term benefits of this agent in heart failure, this was found to be a rational choice. ${ }^{11}$ ACE inhibitor or ARB was prescribed to almost all the patients. According to the standard treatment for heart failure due to any cause, this was also a rational choice. ACEI or ARBs however were not prescribed in a few patients due to their low blood pressure which could be due to low ejection fraction in those patients. ACE inhibitors too provide essential cardiovascular benefits in this group of patients as is seen from the HOPE trial. ${ }^{12}$ Anti-platelet drugs, statins and beta blockers were prescribed frequently as an established part of treatment of these patients. ${ }^{13}$ Among beta blockers carvedilol was preferred over metoprolol as has been noted in other studies as well. Although Atenolol has been used in some cases, Metoprolol or Carvedilol remains a more rational choice of beta blocker in this case scenario. ${ }^{14}$

Ivabradine was also found to be used in $1.54 \%$ cases in our study. This use is supported in recent literature due to its heart rate lowering effect. ${ }^{14-16}$ Ivabradine has a beneficial effect in DCM especially in those who have heart rates not controlled with beta blockers. In few patients due to the heart rate lowering effect of beta blockers, syncope occurred and in those cases Digoxin was used as an alternative. Though the use of Digoxin is well established but in our setting we found a restricted use of Digoxin (only in $5.4 \%$ of prescriptions). ${ }^{17}$ Nearly $11 \%$ of the prescriptions were nitrates or vasodilators that form a rational treatment for heart failure according to most guidelines.

There was around $17 \%$ use of sedatives and anxiolytics and agents that reduce secretion of gastric acids. This could be due to the chronic nature of the disease as well as due to the age group of the study population. Such use was found to be justified. We however noted a high use of multi vitamin agents. Anemia may aggravate heart failure and use of oral iron agents is important in these patients. However unnecessary use of multi-vitamin increases the cost of the therapy.

One of the major limitations of this study was the short duration and the small sample size. This makes drawing any direct conclusion from this study, difficult. However a larger group of patients and prescriptions in the same set up are being followed up at present as part of a larger and more robust study. 


\section{CONCLUSION}

This short and pilot study shows that there was a high prevalence of DCM, mostly among the middle aged and elderly male patients in our setting. This pharmacoepidemiological study provides a picture of the prescribing patterns and drug usage in this patient population. A larger study will provide a good data about the current situation and more intense interventions can be planned for DCM.

\section{ACKNOWLEDGEMENTS}

We would like to thank the faculty and post graduate students of both Departments of Cardiology and Pharmacology for their help and support. We would like to thank the patients who participated in this study.

Funding: No funding sources Conflict of interest: None declared

Ethical approval: The study was approved by the Institutional Ethics Committee

\section{REFERENCES}

1. Ushashree B, Shivani V, Venkateshwari A, Jain RK, Narsimhan C, Nallari P. Epidemiology and genetics of dilated Cardiomyopathy in the Indian context. Indian J Med Sci. 2009;63:288-96.

2. Manolio TA, Baughman KL, Rodeheffer R. Prevalence and etiology of idiopathic dilated cardiomyopathy Am J Cardiol. 1992;69:1458-66.

3. Braunwald E, Zipes DP, Libby. Heart disease. A text book of cardiovascular medicine. 9th ed. Philadelphia. W.B. Saunders Company. 2012:1563-9.

4. World Health Organization Action Programme on Essential Drugs. How to investigate drug use in health facilities: selected drug use indicators. Available at:

http://apps.who.int/medicinedocs/en/d/Js2289e/ (accessed on 10th September 2015).

5. ATC DDD Index. Available at: http://www.whocc.no/atc_ddd_index/ (accessed on 10th September 2015).

6. Deshmukh A, Deshmukh A, Deshmukh G, Garg PK. A pilot study of dilated cardiomyopathy (DCM) in western Uttar Pradesh, India: A four year review. Medico-Legal update. 2011:11. Available at: http://www.indianjournals.com/ijor.aspx?target=ijor: mlu \&volume $=11 \&$ issue $=1 \&$ article $=001 . \quad$ Accessed on 5th February 2016.

7. Rakar S, Sinagra G, Di Lenarda A, Poletti A, Bussani R, Silvestri F et al. Epidemiology of dilated cardiomyopathy: A prospective post-mortem study of 5252 necropsies. European Heart Journal. 1997; 18:117-23.

8. Limas CJ, Limas C, Kubo SH, Olivari MT. Anti beta receptor antibodies in human dilated cardiomyopathy and correlation with HLA-DR antigens. Am J Cardiol. 1990;65:483-6.

9. Bharath DK, Chandrashekhar R, Manohar VR, Rai M, Gopalakrishna HN, Dsouza R. Drug Utilization study in patients with congestive cardiac failure in a South Indian tertiary care hospital: A retrospective study. Int Res J Pharm. 2015;6:463-6.

10. Baskota M, Rao BS, Shakya R. Study on the prescribing patterns of drugs used in heart failure. Kathmandu University Journal of Science, Engineering and Technology. 2006;2:1-10.

11. Margo KL, Luttermoser G, Shaughnessy AF. Spironolactone in Left-Sided Heart Failure: How Does It Fit In? Am Fam Physician. 2001;64:1393-9.

12. Yusuf S, Sleight P, Pogue J, Bosch J, Davies R, Dagenais G. Effects of an angiotensin-convertingenzyme inhibitor, ramipril, on cardiovascular events in high-risk patients. The Heart Outcomes Prevention Evaluation Study Investigators. $\mathrm{N}$ Engl J Med. 2000;342:145-53.

13. Nair M, Sethi KK, Aggarwal R, Arora R, Khalilullah M. Clinical and hemodynamic effects of oral metoprolol in dilated cardiomyopathy. Indian Heart J. 1990;42:411-4.

14. Kurtoglu E, Balta S, Karakus Y, Yasar E, Cuglan B, Kaplan O, et al. Ivabradine Improves Heart Rate Variability in Patients with Nonischemic Dilated Cardiomyopathy. Arquivos Brasileiros de Cardiologia. 2014;103:308-14.

15. Busseuil D, Shi Y, Mecteau M, Brand G, Gillis MA, Thorin $\mathrm{E}$, et al. Heart rate reduction by ivabradine reduces diastolic dysfunction and cardiac fibrosis. Cardiology. 2010;117:234-42.

16. Tardif JC, O'Meara E, Komajda M, Böhm M, Borer JS, Ford I, et al. SHIFT Investigators Effects of selective heart rate reduction with ivabradine on left ventricular remodelling and function: results from the SHIFT echocardiography substudy. Eur Heart J. 2011;32:2507-15.

17. Massin EK. Current Treatment of Dilated Cardiomyopathy. Tex Heart Inst J. 1991;18:41-9.

Cite this article as: Banerjee $\mathrm{P}$, Mandal $\mathrm{A}$, Mukhopadhyay D, Gangopadhyay T, Mandal S, Das A. Assessment of drug utilization pattern and rationality of drug use in treatment of dilated cardiomyopathy in a tertiary care teaching hospital of rural Bengal. Int J Basic Clin Pharmacol 2017;6:1237. 